TABLE II-Outcome in patients with an unsatisfactory initial outcome

\begin{tabular}{lcc}
\hline & \multicolumn{2}{c}{ Patients who had received: } \\
\cline { 2 - 3 } & $\begin{array}{c}\text { Placebo } \\
(\mathbf{n}=27)\end{array}$ & $\begin{array}{c}\text { Ultrasound } \\
(\mathrm{n}=14)\end{array}$ \\
\hline Healed with ultrasound & 8 & 11 \\
Healed with injections & 7 & 1 \\
Healed with ultrasound and injection & 7 & 2 \\
Withdrew while symptomatic & 3 & \\
Referred for surgery to elbow & 2 & \\
\hline
\end{tabular}

TABLE III-Overall outcome at discharge and at review after one year

\begin{tabular}{lcc}
\hline & \multicolumn{2}{c}{ After one year } \\
\cline { 2 - 3 } & Satisfactory & Unsatisfactory \\
\hline $\begin{array}{c}\text { Satisfactory after: } \\
\quad \text { Placebo }(\mathrm{n}=11)\end{array}$ & 6 & 5 \\
$\begin{array}{c}\text { Ultrasound with or without } \\
\text { placebo }(\mathrm{n}=32)\end{array}$ & 29 & 3 \\
$\begin{array}{c}\text { Steroid injection with or without } \\
\text { ultrasound or placebo, or both } \\
(\mathrm{n}=25)\end{array}$ & 13 & 12 \\
$\begin{array}{c}\text { Unresolved or refused further } \\
\text { treatment }(\mathrm{n}=8)\end{array}$ & $2 *$ & $6+$ \\
\hline
\end{tabular}

* Reduced to one patient after surgery.

* Reduced to one patient after surgery.
+ Reduced to two patients after surgery.

may reflect the benefits of careful supervision, increased rest, and natural remission but may also have resulted from the massage effect of the transducer head over the affected area during mock insonation.

Subjective patient assessment immediately after the completion of treatment has usually been used to determine the efficacy of treatment. We, however, found a definite discrepancy between the subjective and objective assessments. Review four to six weeks later showed better agreement. Repetitive activity, especially housework, often precipitated onset, and failure to rest from this activity resulted in poor response. Although Dyson et al, using an animal model, ${ }^{4}$ suggested that maximum benefit could be obtained from starting treatment as early as possible, we could detect no advantage in patients who presented early.

Clarke and Stenner ${ }^{15}$ and Allen and Battye ${ }^{16}$ noted considerable changes in ultrasonic output with time. Using a simple underwater balance, we confirmed these changes in radiation output emphasising the need for frequent assessment. Ultrasound is time consuming to patient and therapist, and further controlled studies in other conditions are necessary. Previously we have shown that clinical and thermographic changes reflect severity of lateral epicondylitis. ${ }^{14}$ It therefore is a useful model for the assessment of therapeutic measures such as ultrasound.

\section{References \\ 1 Wood RW, Loomis AL. The physical and biological effects of high-frequency sound waves of great intensity. London, Edinburgh, Dublin philosophical Magazine and fournal of Science 1927;4:417-36. \\ Lehmann JF, Warren CG, Scham SM. Therapeutic heat and cold. Clin Orthop \\ 3 Harvey W, Dyson $M$, Pond JB, Grahame R. The stimulation of protein synthesis in human fibroblasts by therapeutic ultrasound. Rheumatol Rehabil 1975;14: \\ Dyson $\mathrm{M}$, Pond JB, Joseph J, Warwick $\mathrm{R}$. The stimulation of tissue regeneration by means of ultrasound. Clin $S_{c i} 1$ 1968;35:273-85. \\ Aldes $\mathrm{JH}$. Ultrasonic radiation in the treatment of epicondylitis. General Pructitioner 1956;13:89-96. \\ 6 Lehmann JF, Erickson DJ, Martin GM, Krusen FH. Comparison of ultrasonic and microwave diathermy in the physical treatment of periarthritis of the shoulder. Archives of Physical Medicine 1958;35:627-38. \\ 7 Munting E. Ultrasonic therapy for painful shoulders. Physiotherapy 1978;64: $180-1$. \\ 8 Flax $\mathrm{HJ}$. Ultrasound treatment of peritendinitis calcarea of the shoulder. Am F Phys Med 1964;43:117-24 \\ Mueller EE, Mead S, Schultz BF, Vaden MR. Symposium on ultrasonics; a placebo-controlled study of ultrasound treatment for periarthritis. Am $\mathcal{F}$ Phys Men $M$ Franks C,

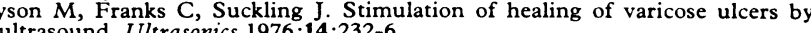 \\ . $232-6$ \\ 11 Lehmann JF, De Lateur BJ, Warren CG, Stonebridge JB. Healing produced by ultrasound in bone and soft tissue. Archives of Physical Medicine 1967:48: 397-401. \\ 12 Lunt MJ, Ashley B. A simple radiation balance for measuring ultrasonic power. 7 Med Eng Technol 1979;3:194-7. \\ 13 Binder AI, Hazleman BL. Lateral humeral epicondylitis-a study of natural history and the effect of conservative therapy. Brf Rheumatol 1983;22:73-6. der A, Parr G, Thomas DP, Hazleman B. A clinical and thermographic study of lateral epicondylitis. Br f Rheumatol 1983;22:77-81. \\ 15 Clarke GR, Stenner L. Use of therapeutic ultrasound. Physiotherapy 1976;62 : 85-90. \\ 16 Allen KGR, Battye CK. Performance of ultrasonic therapy instruments. Physiotherapy 1978;64:174-9. \\ (Accepted 13 November 1984)}

\title{
Assessment of dermal glyceryl trinitrate and isosorbide dinitrate for patients with angina pectoris
}

\author{
PETER J B HUBNER, PETER R M JONES, IAN A R GALER
}

\begin{abstract}
Dermal nitrate preparations are claimed to be useful in the treatment of angina, as their slow absorption bypassing the liver leads to a sustained action. Ten patients with angina were exercised on a treadmill after dermal application of $16.64 \mathrm{mg}$ glyceryl trinitrate or $100 \mathrm{mg}$ isosorbide dinitrate or placebo. Exercise duration was significantly increased at one and three hours for both
\end{abstract}

Department of Cardiology, Groby Road Hospital, Leicester LE3 9QE PETER J B HUBNER, MB, MRCP, consultant cardiologist

Department of Human Sciences, Loughborough University of Technology, Leicestershire LE11 3TU

PETER R M JONES, MSC, PHD, reader in human functional anatomy

IAN A R GALER, BSC, MSC, lecturer in ergonomics

Correspondence and requests for reprints to: Dr P J B Hubner. nitrate preparations but not at six hours after application. The calculated workload achieved was significantly increased $(p<0.01)$ at one and three hours for both preparations and at six hours $(p<0.05)$ for isosorbide dinitrate. Headaches were common with glyceryl trinitrate cream. The dermal nitrate preparations studied had a duration of antianginal action similar to that of oral nitrate tablets.

Aside from their value when the oral route cannot be used or absorption may be delayed, dermal nitrate preparations have no advantage over oral preparations for angina pectoris.

\section{Introduction}

When glyceryl trinitrate and isosorbide dinitrate are taken by mouth they are absorbed by the intestines and pass to the liver, where they are partially broken down. This "first pass" metabolism limits the duration of action of oral nitrates," though 
this view has been challenged. ${ }^{2}$ The dermal route of administration allows a slow, prolonged, and direct absorption into the bloodstream, bypassing the liver.

Prolonged antianginal action of three to eight hours has been claimed for dermal glyceryl trinitrate ${ }^{34}$ and up to seven hours for the more recently introduced isosorbide cream. ${ }^{5}$ Cheadle et al, however, failed to show any prolonged action for dermal isosorbide. ${ }^{6}$ Many of the reported studies have not used a control group, and there has not been a direct comparison between the two dermal nitrates. We have conducted a controlled double blind study to assess and compare dermal glyceryl trinitrate and isosorbide dinitrate.

\section{Patients and methods}

We studied 10 men aged $38-62$ years (mean 53 ) with severe stable angina. The purpose and methods of the study were explained but the patients were not informed that one of the preparations would be a . placebo. The design and protocol of the trial were approved by the ethics committee of the Leicester Health Authority. All patients had angina on a treadmill exercise test and nine also had significant ST depression. Five patients were receiving $\beta$ blocking drugs, nifedipine, and oral nitrates; two were receiving $\beta$ blocking drugs and oral nitrates; one was receiving $\beta$ blockers alone; and two were taking only oral nitrates.

Angina had been present for an average of 2.3 years (range three months to five years). Two patients had had documented myocardial infarction three and six years before the study. Two patients had changes in the electrocardiogram suggestive of previous subendocardial infarction, but neither had had a clinical event. Nine patients had angiographically proved coronary artery disease (five triple, three double, and one single vessel disease). Three had normal left ventricular function, and six had mild to moderate dysfunction on the left ventricular angiogram. The tenth patient, who did not undergo coronary angiography, had a documented myocardial infarct and had ST depression on the exercise test.

The patients were admitted to hospital for the study. On day 1 all antianginal treatment was stopped without incident. The patients were given a small personal supply of glyceryl trinitrate tablets, but these were not used within four hours before or during a period of exercise testing. On each of days 1 to 4 an exercise test was performed to accustom patients to this method of assessment. The patients were brought in a wheelchair for exercise testing, which was performed on a treadmill (Quinton 18-54) using the Sheffield (modified Bruce) protocol. ${ }^{7}$ This is a staged exercise test in which the workload is increased every three minutes. The end point of the exercise was the development of moderately severe angina so that the patient wished to stop walking.

TABLE I-Duration of exercise (seconds)

\begin{tabular}{lccc}
\hline & Placebo & $\begin{array}{c}\text { Glyceryl } \\
\text { trinitrate }\end{array}$ & $\begin{array}{c}\text { Isosorbide } \\
\text { dinitrate }\end{array}$ \\
\hline 1 Hour mean (SEM) & $377(52)$ & $523(79)$ & $454(78)$ \\
\%o Increase & & 39.01 & 20.05 \\
p Value* & $365(60)$ & $492(64)$ & $483(70)$ \\
Hour mean (SEM) & & 35 & 32 \\
\%o Increase & $375(58)$ & $427(72)$ & 20.01 \\
p Value* & & 14 & $455(67)$ \\
6 Hour mean (SEM) & & NS & 21 \\
\% Increase & & NS \\
p Value* & & & \\
\hline
\end{tabular}

NS = Not significant

Dermal nitrate $v$ placebo.

TABLE II-Total workload $(\mathrm{kpm})$

\begin{tabular}{lccc}
\hline & Placebo & $\begin{array}{c}\text { Glyceryl } \\
\text { trinitrate }\end{array}$ & $\begin{array}{c}\text { Isosorbide } \\
\text { dinitrate }\end{array}$ \\
\hline 1 Hour mean (SEM) & $1010(282)$ & $2410(878)$ & $1855(776)$ \\
$\%$ Increase & & 138 & 84 \\
p Value & $1034(388)$ & $1896(425)$ & $<0.01$ \\
3our mean (SEM) & & 83 & $1930(642)$ \\
\% Increase & & 80.01 & 87 \\
p Value & $1047(306)$ & $1549(522)$ & $1699(570)$ \\
6 Hour mean (SEM) & & 48 & 62 \\
\% Increase & & NS & $<0.05$ \\
p Value & & & $<0.05$ \\
\hline
\end{tabular}

TABLE III-Mean time to relief of angina (seconds). (SEM in parentheses)

\begin{tabular}{lccc}
\hline & Placebo & $\begin{array}{c}\text { Glyceryl } \\
\text { trinitrate }\end{array}$ & $\begin{array}{c}\text { Isosorbide } \\
\text { dinitrate }\end{array}$ \\
\hline 1 Hour & $94(15)$ & $94(13)$ & $96(9)$ \\
3 Hour & $101(12)$ & $110(17)$ & $84(10)$ \\
6 Hour & $115(14)$ & $113(18)$ & $104(15)$ \\
\hline
\end{tabular}

TABLE IV-Headaches with preparations (numbers of patients)

\begin{tabular}{lccc}
\hline & Placebo & $\begin{array}{c}\text { Glyceryl } \\
\text { trinitrate }\end{array}$ & $\begin{array}{c}\text { Isosorbide } \\
\text { dinitrate }\end{array}$ \\
\hline Sild & 1 & 1 & 3 \\
Severe & 0 & 6 & 0 \\
\hline
\end{tabular}

On days 5,6 , and 7 at 830 am a dermal preparation of placebo or $16.64 \mathrm{mg}(2.5 \mathrm{~cm})$ glyceryl trinitrate $2 \%$ (Percutol) or $100 \mathrm{mg}$ isosorbide dinitrate (Isoket) was applied in random order to the skin over the anterior chest by a doctor not concerned in the exercise testing. The placebo and isosorbide dinitrate were applied as a cream over an area $9 \mathrm{~cm}$ square and covered by a $10 \times 10 \mathrm{~cm}$ gauze swab secured with Micropore tape. Glyceryl trinitrate was squeezed on to an Applirule, which was placed on the skin and covered by a gauze swab. One, three, and six hours later exercise testing was performed. Patients were fasted for the initial test and then given a light breakfast. The duration of exercise and time to relief of angina after the end of exercise were recorded. After the final test the patients were asked if they had noticed any side effects.

The work performed during the exercise test was calculated as: work performed (kilopond metres $/$ minute $; \mathrm{kpm} / \mathrm{min}$ ) = body weight $(\mathrm{kg}) \times \%$ treadmill gradient $\times$ speed $(\mathrm{m} / \mathrm{min}) .{ }^{8}$ The work performed at each stage of the protocol was summed to obtain the total work achieved by the time the patient completed the test. Thus if a patient walked for eight minutes the work performed was that of three minutes (stage 1) plus three minutes (stage 2) plus two minutes (stage 3 ).

Student's $t$ test for related samples was used for statistical analysis of exercise duration and time to relief of angina. As there were large differences among patients in the total work performed the parametric assumptions of the $t$ test could not be made and the Wilcoxon matched pair signed rank test was used for its analysis.

\section{Results}

Exercise duration (table I) was significantly increased for both glyceryl trinitrate and isosorbide dinitrate at one and three hours after application compared with the times for the placebo. The increase was not significant at six hours. The increase for isosorbide dinitrate over placebo at six hours was $21 \%$ (compared with $20 \%$ at one hour) and just failed to reach significance at the $5 \%$ level. The standard error of the differences in exercise duration between paired values of isosorbide dinitrate and placebo was greater at 0.618 for six hours compared with 0.489 for the results after one hour.

Total workload performed (table II), which takes into account both exercise duration and increase in workload at progressive stages of the protocol, was significantly increased $(p<0.01)$ for both nitrate preparations at one and three hours and for isosorbide dinitrate at six hours $(\mathrm{p}<0.05)$.

Time to relief of angina (table III) was not reduced by either nitrate preparation. The only side effects (table IV) were headaches, which were both frequent and severe with glyceryl trinitrate. No skin reactions occurred.

\section{Discussion}

Both preparations of dermal nitrate were shown to have an antianginal action at one hour, which was maintained to three hours, and to have some action up to six hours. The methods used in the study were strict and removed the placebo effect of merely recording increase in exercise over a control test by the treatment. ${ }^{4}$ The increases in total workload achieved over placebo were large $(62-138 \%$; table II) and represented a clear antianginal effect of the dermal nitrate preparations. The increases of exercise duration over placebo were smaller (20-39\%), but 
this variable does not take into account the increase in workload performed at the progressive stages of the exercise test.

Headaches, the usual side effect of nitrate preparations, were prominent with glyceryl trinitrate and confirmed absorption of the drug. Some patients find that when using a dermal nitrate their angina is more quickly relieved after stopping exercise. This was not confirmed in our study as anginal pain passed off no sooner with the dermal nitrate than with the placebo (table III). Interestingly, however, angina was promptly relieved after stopping exercise (1.68 (SEM 0.23) minutes) compared with the usual description of angina lasting five to 15 minutes.

The exact role of dermal nitrates for patients with angina is uncertain. The duration of action of the two preparations assessed in this study was no longer than with oral preparations of glyceryl trinitrate $8.4 \mathrm{mg}$ (Sustac) ${ }^{9}$ or isosorbide dinitrate $20 \mathrm{mg},{ }^{10}$ and headaches still occurred. The preparations assessed were comparatively messy and inconvenient to use. New preparations incorporating the nitrate within a slow release plaster are claimed to have a longer duration of action and are certainly simpler to use. ${ }^{11}$ These preparations, however, are expensive and are apt to become displaced. Though sometimes recommended for nocturnal angina, ${ }^{12}$ the duration of action of up to six hours found for dermal nitrates in this study suggests that they would not be active throughout sleep. There has been no study for nocturnal angina comparing a dermal nitrate with an oral preparation or with a mild diuretic given in the evening.

Dermal nitrates are of undoubted value when the oral route cannot be used or when absorption may be delayed, such as before, during, or after surgery or cardiac catheterisation, in unstable angina and acute myocardial infarction, and in patients with severe heart failure. Outside these conditions no advantage has been shown for dermal over oral nitrate preparations for patients with angina pectoris.

We thank Drs J Anderson, I Aston, M Goldberg, J Walker, and M Khalil for their help with this work.

\section{References}

1 Needleman P, Lang S, Johnson EM. Organic nitrates: relationship between biotransformation and rational angina pectoris therapy. $\mathcal{A}$ Pharmacol Exp Ther $1972 ; 181: 489-97$.

2 Abrams J. Oral long acting nitrates in angina pectoris and the rationale for high dose therapy. Br 7 Clin Pract 1981 ;suppl 12:39-43.

3 Reichek N, Goldstein RE, Redwood DR, Epstein SE. Sustained effects of nitroglycerin ointment in patients with angina pectoris. Circulation 1974;50:348-52 Davidov ME. Cutaneous administration of nitroglycerin in patients with angin pectoris. Angiology 1981;32:16-20.

5 Brunner D, Weisbord J, Nissenman G, Klinger J. Sustained effect of isosorbide dinitrate ointment on angina and exercise-induced electrocardiographic changes in patients with ischaemic heart disease. Nitrates III: cardiovascular effects. Berlin, Heidelberg: Springer-Verlag, 1981:411-8. becomes an opportunity. Br Med f 1981;283:1549.

7 Sheffield LT. Graded exercise test (GXT) for ischemic heart disease. In: Lichtlen PR, Engel H-J, Schrey A, Swan HJC, eds. Exercise testing and training of apparently healthy individuals: a handbook for physicians. The Committee on Exercise, American Heart Association, 1972: 35-8.

8 Sheffield LT. Exercise stress testing. Heart disease. In: Braunwald E, ed. $A$ textbook of cardiovascular medicine. Philadelphia, London, Toronto: WB
Saunders Co, 1980:260.

9 Richardson PJ. Medical treatment of angina pectoris; the place of Sustac alone or in combination with propranolol in the treatment of stable angina pectoris interim report of a clinical study. Br f Clin Pract 1981;suppl 12:29-34.

10 Thadani U, Fung H-L, Darke AC, Parker JO. Oral isosorbide dinitrate in the treatment of angina pectoris. Circulation $1980 ; 62: 491-502$.

11 Imhof PR. The pharmacology of Transiderm-Nitro. In: International congress and symposium series of the Royal

12 Anonymous. Nitroglycerin ointment [Editorial]. Lancet 1976;ii:1287.

(Accepted 26 November 1984)

\section{SHORT REPORTS}

\section{Persistent nephrogenic diabetes insipidus, hyperparathyroidism, and hypothyroidism after lithium treatment}

Nephrogenic diabetes insipidus, hyperparathyroidism, and hypothyroidism are well recognised complications of lithium treatment that are generally considered to be reversible. ${ }^{1}$ We describe what we believe to be the first recorded case of a patient suffering all three conditions concomitantly and persistently despite withdrawal of lithium.

\section{Case history}

A 43 year old woman began treatment with lithium carbonate for mania in 1973. She continued treatment with irregular monitoring of serum lithium concentrations until her admission to Edgware General Hospital in November 1981. At presentation she was dehydrated, drowsy, and confused with choreoathetoid movements. Results of investigations were: serum lithium concentration $2.6 \mathrm{mmol} / 1(1.8 \mathrm{mg} / 100 \mathrm{ml}$; therapeutic range $0.5-1.5 \mathrm{mmol} / 1$ $(0.3-1.0 \mathrm{mg} / 100 \mathrm{ml}))$, serum calcium concentration $3.0 \mathrm{mmol} / 1(12.0 \mathrm{mg} /$ $100 \mathrm{ml}$ ), and normal serum phosphate, decreased serum thyroxine, raised serum thyrotrophin, and raised serum parathyroid hormone concentrations. Correction of fluid balance and thyroid replacement led to clinical and biochemical improvement except for the serum calcium value, which remained mildly raised. She was discharged and subsequently took no more lithium.

In July 1982 she presented to another hospital for investigation of dehydration, polyuria, and polydipsia. Investigation confirmed hypercalcaemia $(2.7 \mathrm{mmol} / 1(10.8 \mathrm{mg} / 100 \mathrm{ml}))$ with raised serum parathyroid hormone concentration. In addition, nephrogenic diabetes insipidus was diagnosed by a water deprivation test, during which there was a greater than $3 \%$ loss of total body weight with failure to increase the urinary osmolality above $167 \mathrm{mmol}(\mathrm{mosmol}) / \mathrm{kg}$ water. There was no increase in urinary osmolality after nasal administration of desmopressin. Furthermore, the plasma arginine vasopressin concentration was greatly increased at $29.7 \mathrm{pmol} / 1$
$(32 \cdot 2 \mathrm{pg} / \mathrm{ml})$, and water rehydration decreased this. Creatinine clearance was $40 \mathrm{ml} / \mathrm{min}$, and an intravenous urogram was normal. Serum urea and creatinine values were normal.

In October 1983 she was admitted drowsy and dehydrated. She was taking only thyroxine $125 \mu \mathrm{g}$ daily. Serum calcium concentration was $2.8 \mathrm{mmol} / \mathrm{l}(11.1 \mathrm{mg} / 100 \mathrm{ml})$, serum magnesium concentration normal, and serum parathyroid hormone concentration $850 \mathrm{pg} / \mathrm{ml}$ (normal $<120$ $\mathrm{pg} / \mathrm{ml}$ ). There was no biochemical or radiological evidence of hyperparathyroid bone disease. Correction of fluid balance produced a biochemical improvement except for the raised serum calcium value. Her clinical state was complicated by mania.

The combination of diabetes insipidus, hypercalcaemia, and mania presented formidable problems in maintaining fluid balance, and we therefore considered parathyroidectomy to control the hypercalcaemia. We also hoped that correction of the hypercalcaemia would improve her mental state. ${ }^{2}$ No adenoma was found at operation, but histological examination showed hyperplasia of all parathyroid glands. Parathyroidectomy and return of the serum calcium value to normal did not help the control of fluid balance or improve her mental state.

During March 1984 she deteriorated mentally, became dehydrated, developed bronchopneumonia, and died.

\section{Comment}

Our patient had three persistent metabolic conditions-nephrogenic diabetes insipidus, hypothyroidism, and hyperparathyroidism-after documented lithium toxicity, suggesting that lithium was responsible. These disorders are generally recognised as reversible on stopping lithium, although there are a few reports of persistent diabetes insipidus ${ }^{3}$ and hyperparathyroidism. ${ }^{2}$ Our patient continued lithium for almost eight years with irregular monitoring of serum concentrations, and it seems likely that prolonged exposure to possibly high concentrations of lithium led to irreversible changes in the thyroid and parathyroid glands and the renal tubules. Serum lithium concentrations within the therapeutic range may, however, be associated with the development of toxicity. ${ }^{1}$ Hypercalcaemia was an unlikely cause for the diabetes insipidus because the disorder persisted postoperatively when she was normocalcaemic.

This case re-emphasises the importance of regular monitoring of 